\title{
Bringing the Cross Pressures Thesis into the Digital Realm: Subjective Social Network Heterogeneity and Online Political Expression
}

\section{Matthew David Jenkins}

Author ORCID Nr: 0000-0002-3999-2591

Gyeongsang National University, Republic of Korea; mjenkins@gnu.ac.kr

\begin{abstract}
Approaches to social network heterogeneity in political communication research tend to focus on the effect of accumulated interactions among individuals with different political views. This line of research has provided a number of rich insights into the nature of the relationship between sociality and political participation. At the same time, this research tradition has been hampered by inconsistent terminology, and it has not been updated to reflect the fact that the experience of engaging with politics through digital media produces a unique subjective experience wherein the user is made to address an imagined audience with a perceived set of characteristics. In this study I aim to accomplish three main objectives. First, I propose an adjustment to the conceptual framework used in the literature. Second, I introduce the concept of subjective social network heterogeneity to describe perceived heterogeneity in the political views of the imagined audience. Third, I investigate the relationship between subjective social network heterogeneity and political expression empirically, through an analysis of original survey data from Japan and South Korea. The results show that differences between the political views of an individual and the perceived political views of the imagined audience depresses political expression on social media in both countries, but that variance in the perceived views of the imagined audience is positively associated with political expression.
\end{abstract}

Keywords: Social media; heterogeneity; political expression

Acknowledgement: I wish to thank the anonymous reviewers for their helpful comments.

\section{Introduction}

Many theories of democracy posit that the interaction of politically diverse individuals is fundamental to maintaining or producing democracy. By some accounts, the critical type of interaction is political deliberation, owing to the way it leads to the emergence of well-considered public opinions (e.g., Habermas, 1996). Interaction between politically diverse individuals and groups can also be 
thought of as an essential aspect of a healthy democratic culture because it is related to norms of tolerance (Almond \& Verba, 1963).

This recognition of the importance of interaction among politically diverse individuals and populations - also referred to as "cross-pressures" or "social network heterogeneity" - has motivated a long line of social scientific research. Although this research has produced contradictory results, existing studies of the effect of cross-pressures have greatly advanced our understanding of the relationship between network heterogeneity and political participation. At the same time, our conceptual framework for understanding this relationship remains rooted in the pre-digital era, based as it is on traditional notions of social groups, the accumulated influence of social interactions, and traditional forms of political participation. While this framework is still useful, it is important to recognize that individuals today are enmeshed in global digitally-mediated networks that individuals in the 1940s were not. Many people now interact with politics, political information, and each other almost entirely through digital media and social media platforms like Twitter, Facebook, and Instagram.

While researchers have updated some aspects of the cross-pressures research paradigm to reflect these changes, these updates have not gone quite far enough. Social media affords a social context for political engagement that is fundamentally different than that envisioned in the cross-pressures tradition. As Marwick and boyd (2011) point out, social media melds multiple social networks into an ambiguous mass audience, complicating self-presentation and the targeting of specific social groups with tailored messages. Faced with the prospect of context collapse, social media users resort to constructing "imagined audiences" in order to facilitate coherent self-presentation, such as by imagining a specific subset afforded by a given platform (e.g., Schulz et al., 2020). The literature does not provide much theoretical guidance with regard to understanding how this imagined audience might affect political participation or political expression in the digital realm.

In this study, I consider the implications of this insight for the relationship between social network heterogeneity and political expression. I begin by proposing a reorganization of the conceptual framework used in the literature in order to establish a general network heterogeneity typology. Secondly, I address the issue of how the imagined audience concept can be incorporated into this framework. I argue that if people do indeed tend to construct an imagined audience from their digital contacts, then they ought also to be able to form an idea of the distribution of political views of this audience. I refer to the perceived variance of this distribution as subjective social network heterogeneity. I further argue that subjective social network heterogeneity ought to affect one's willingness to engage in online political expression. Finally, I test these expectations with survey data from South Korea and Japan. The results of the analysis suggest that perceived political difference between individuals and the imagined audience is negatively associated with political expression in both countries, but that perceived diversity in the political views of the imagined audience is positively associated with political expression, though the results vary by country. I conclude by discussing the implications of these results and propose avenues for further study. 


\section{Literature Review}

In this section, I develop a new theoretical approach to approach to social network heterogeneity. I begin with an overview of the cross-pressures research tradition. I then review the various operational definitions and measures of social network heterogeneity that have been used in studies that examine the relationship between network heterogeneity and political participation, broadly conceived. I consider the limitations of these approaches in the context of the digital media environment, and I draw on emerging theories of sociality to develop an extension of this tradition that better accommodates the way politics and sociality is commonly experienced today.

\subsection{Social Network Heterogeneity and Political Participation}

Interest in the effect of network heterogeneity on political participation can be traced to the seminal work of Paul Lazarsfield and colleagues (1948), which argued that cross-cutting pressures, or conflicting social pressures resulting from membership in politically disparate groups, depresses or delays political participation because it induces uncertainty, for example, regarding choice of presidential candidate. While this initial formulation of the cross-pressures hypothesis failed to find empirical support, it was revived and refined by Mutz (2002), who showed that the hypothesis could be better evaluated using direct measures of social network heterogeneity. Mutz (2002) found that, after disentangling heterogeneity from group membership, discussion with politically divergent alters does indeed have the negative effect postulated by Lazarsfield et al. (1948). This version of the cross-pressures hypothesis has found some additional empirical support (e.g., Eveland \& Hively, 2009; Huckfeldt, Mendez, \& Osborn, 2004).

Literature supporting what I will refer to as the "negative" cross-pressures thesis offers two main reasons why network heterogeneity should be expected to have this effect: attitude ambivalence and fear of alienation. Firstly, exposure to counter-attitudinal viewpoints can lead to opinion ambivalence (Hochshild, 1981; Zaller, 1992), which in turn causes them to delay political decisions (Mutz, 2002). Second, an individual surrounded by competing views may feel reluctant to pick a side, since doing so might alienate proponents of the opposing side (Green, Viser, \& Tetlock, 2000). This second argument is supported by an adjacent research tradition that is rooted in Noelle-Neuman's (1993) "spiral of silence" (SoS) theory, which argues that individuals withhold expression of their opinion if they sense that they are in the minority on a given issue, owing to the fear that expression of a minority opinion will lead to ostracism. The primary difference between these two traditions concerns the issue of majority opinion status. ${ }^{1}$

Proponents of the "positive" cross-pressures thesis, meanwhile, argue that network heterogeneity should actually work in favor of political participation and expression. They offer four main reasons why this is the case: post-hoc information seeking, persuasion, correction, and identity affirma-

\footnotetext{
${ }^{1}$ For proponents of the SoS, self-censorship is a result of feeling that one holds a minority opinion, whereas proponents of the cross-pressures thesis typically do not specify a specific distribution of opinions that results in the effect. Yet both research traditions rely on the assumption that people will withhold expression or judgment when faced with the prospect of social sanction.
} 
tion. Exposure to competing viewpoints can stimulate interest in politics, which is positively associated with various types of participation. And, while such exposure may cause opinion ambivalence, people might search for additional political information in order to resolve this ambivalence (Huckfeldt, 2004), which behavior is in turn associated with political participation (Scheufele et al., 2004). Individuals may also be motivated to engage in political expression by the desire to correct what they perceive as misinformation posted by others online (Sun et al., 2008), or to persuade politically divergent others (Thorson, 2014). Finally, a number of studies show that individuals may engage in political expression in order to boost the representation of particular views (Correa \& Jeong 2011; Livingstone 2008).

\subsection{Advancing the Framework: Issues of Definition and Imagination}

I identify two issues limiting progress on cross-pressures research: 1) vacillation in the meaning of heterogeneity, and 2) insufficient theorization of the interaction between the digital environment, heterogeneity, and political engagement. In this sub-section I address the first issue by suggesting a reorganization of the heterogeneity concept. I address the second issue by rethinking the way we conceptualize heterogeneity in a digital environment.

The lack of adherence to a consistent conceptual framework capable of dealing with various forms of heterogeneity has hampered scientific consensus on the relationship between heterogeneity and political participation and expression. One major problem in this regard is the erosion of the distinction between context, network composition, and the intensity of dyadic flow. The cross-pressures literature exhibits a tendency to discuss studies that examine the intensity of exchange across a certain subset of nodes in a social network in the same vein as studies that examine network composition. In order to avoid conceptual confusion, I suggest that we maintain the distinction between overall social network composition, subnetwork composition, intensity of flow across dyads, and the broader social context in which the network exists (what Schuefele et al. (2006) refer to as "social context" (Schuefele et al., 2006: p.732)).

A related issue is the expanding vocabulary used to differentiate between ego-alter differences and variance among alters. Eveland and Hively (2009) disaggregate "discussion heterogeneity" according to whether the variance or difference in views is in reference to ego or in reference to alters only, that is, whether it concerns difference between an individual and their discussion partners, or whether it only concerns variance in the views of one's discussion partners. They define "dangerous discussion" as political discussion with politically divergent others, and safe discussion as discussion with like-minded political discussion partners. "Discussion diversity", by contrast, is defined as the extent of variation in the views of one's discussion network, irrespective of difference from ego.

Nir (2011) further disaggregates ego-discussion partner political difference according to whether ego-alter disagreement is total, or whether there is a mix of alters with counter-attitudinal and proattitudinal views. Nir argues that such a classification is warranted in part by experimental studies that show a stark contrast between the effects of complete network disagreement and mixed disagreement, wherein at least one alter has views that comport with those of ego (Asch, 1951). 
While Nir's empirical results suggest that the distinction between complete oppositionality and partial oppositionality can be important, defining oppositionality in this way creates some theoretical difficulties. Above all, it is not clear that oppositionality defined this way can be considered a form of "heterogeneity". Indeed, it would seem that it is better thought of as a specific case of complete network homogeneity, given that it suggests total homogeneity of one's alters. It can also be thought of as a kind of polarization, in so far as it refers to a network with only two opposed political predispositions. This definition presents a case of conceptual stretching insofar as the word "heterogeneity", in both its common usage and its usage in the social networks literature, is widely used to indicate something close to "mixed". The first seven synonyms of heterogenous in Merriam Webster, for example, are "assorted", "eclectic", "indiscriminate", "kitchen-sink", "magpie", "miscellaneous", and "mixed". And, while it is easy to operationalize oppositionality given a particular definition of political difference, the cutoff point between "mixed" and "oppositional" presents theoretical and empirical difficulties. On the theoretical side, one would be hard-pressed to explain why someone who disagrees about politics with $90 \%$ of their discussion partners would be significantly less predisposed to conformity than an individual who disagrees with $99 \%$ or $100 \%$ of their discussion partners.

The point here is not that oppositionality is not a useful concept, but that it is better thought of as a continuum, rather than a discrete category. That is, we ought to repurpose "network oppositionality" as our definition of alter-ego difference. Network oppositionality has two primary advantages over other terms. First, it connotes the underlying meaning of these other terms in a direct, accessible, and less informal manner, as the essence of "risky" in risky discussion is that alters are politically opposed to ego on some ideological or issue dimension. Second, it can be used to refer both to compositional heterogeneity and discussion heterogeneity, whereas "dangerous discussion" cannot be used unambiguously to refer to compositional heterogeneity. We can then define "complete oppositionality" as simply the point at the far end of the oppositionality spectrum where all alters are different from ego.

Defining network oppositionality in this way - as the extent of political difference between ego and alters - permits the development of an holistic but flexible typology of social network heterogeneity. This is presented in Table 1. Hereafter, I will adhere to the typology proposed in Table 1. 
Table 1. Social Network Heterogeneity Typology

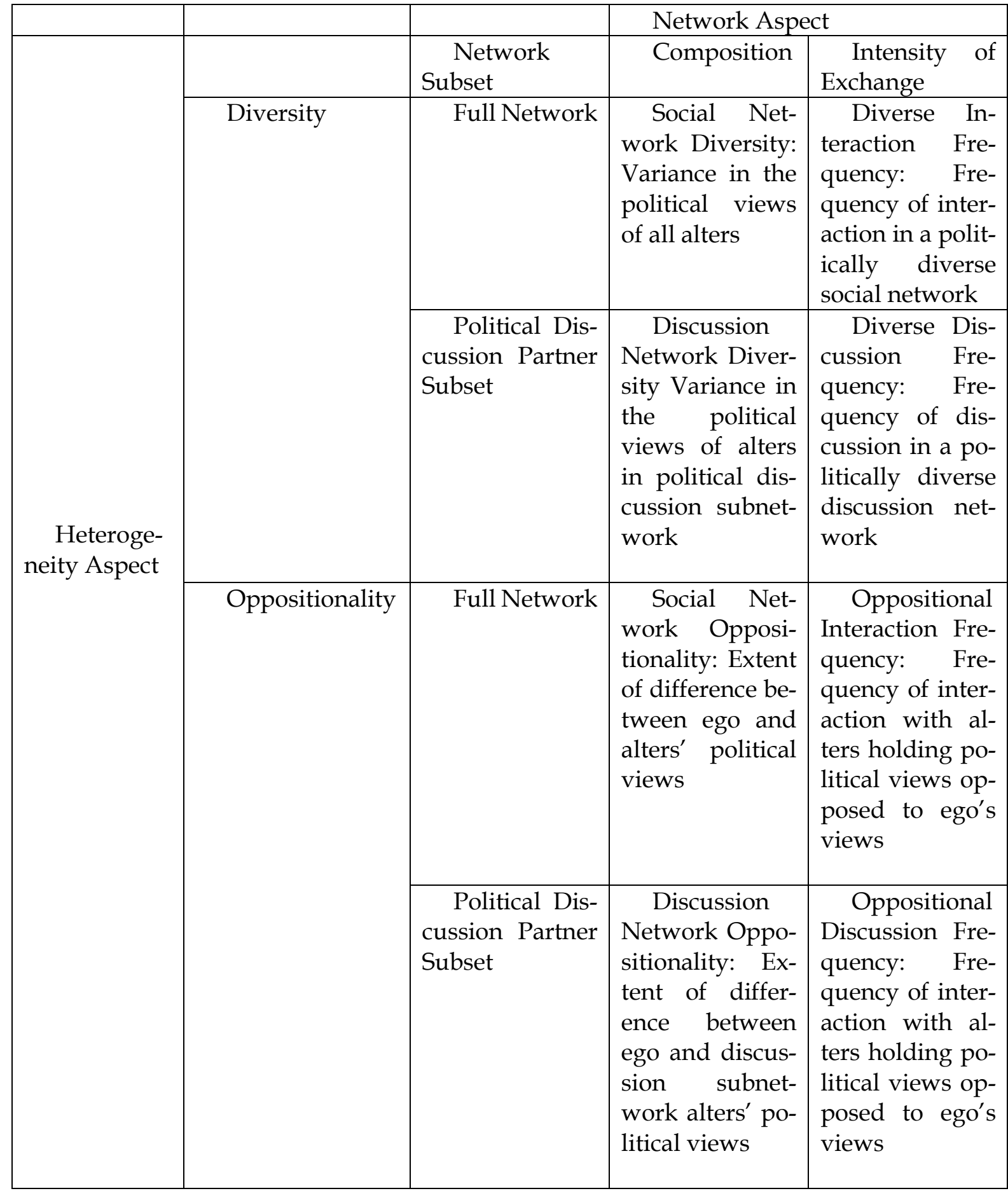

A second issue that has prevented further scientific progress is the incomplete theorization of the relationship between heterogeneity and political engagement in the context of an online environment. Much of the cross-pressures debate concerns the effects of real-world social interaction (i.e., social gatherings, discussion, etc.) on real-world institutional political participation (i.e., voting, posting campaign bumper stickers, donating to campaigns, etc.). Although scholars have since begun to include the digital counterparts of these variables in their analyses, the common approach to 
cross-pressures does not always fully capture the nature of environments in which individuals interact with each other and in which they participate in politics. Specifically, it does not fully reckon with the changes that digital media - and social media in particular - has wrought on political participation and social interaction.

Digital media has become one of the primary environments in which people encounter political phenomena. Even those who are uninterested in politics are likely to be exposed to a variety of political messages and political information on the internet (Bakshy et al., 2015; Barberá, 2014; Eady et al., 2019; Fletcher, Cornia, \& Kleis Neilson, 2019; Guess, 2020; Nechushtai \& Lewis, 2019). It also offers a myriad of affordances for political engagement, including low-cost methods of participation and expression, or what is sometimes referred to as "clicktivism" (Halupka, 2017). Individuals can share political memes (Highfield \& Leaver 2016), post or comment about politics on social media platforms or news media websites (Thorson et al., 2013), and engage in other forms of political expression. In addition to influencing popular understanding of political issues (Chadwick, 2017; Thorson \& Wells, 2015), these affordances are important because they can affect the success of realworld political actions by encouraging the spread of information and contributing to the coordination of offline mass action (Margetts et al., 2015; Steinert-Threlkeld, 2017).

The changes in social interaction that social media has brought about are perhaps even more consequential for the cross-pressures tradition. Among these changes is the way social media reorganizes and structures social interactions by bringing together multiple subnetworks that in the predigital era one typically interacted with separately. As Marwick and boyd (2011) argue, social media causes distinct subnetworks (friends, family, acquaintances, etc.) to collapse into a single hazy social mass, resulting in what is known as "context collapse" (Marwick \& boyd, 2011). This collapse of disparate social contexts complicates self-presentation in so far as it makes it difficult or perhaps impossible to address a single subnetwork with messages designed specifically for that group or individuals in it. Marwick and boyd (2011) argue that this in turn forces individuals to create in their minds an "imagined audience" out of an amorphous digitally-mediated social mass in order to construct meaningful messages. This imagined audience can arguably be viewed as a subset of alters, but it is fundamentally different from a simple subset of alters in that it is an idiosyncratic amalgamation of alters that is unique to the individual; it is a construction of their imagination, a conversational bubble intended to make online interaction meaningful.

Clearly, an imagined audience is very different from the distinct subnetworks envisioned in the cross-pressures tradition. This is not to say that the traditional approach is irrelevant. Rather, the point here is that this imagined audience may have its own distinct effect on the decision to engage in politics or political expression online, since it is before this audience that one must speak and act. In other words, it is possible that individuals have some notion of the characteristics of this imagined audience in mind when they decide to engage in politics online, and that these perceived characteristics influence this decision. ${ }^{2}$ Specifically, people may have a subjective sense of the extent of polit-

\footnotetext{
2 Schulz et al. (2020), for instance that the political ideology of one's followees on Twitter affects the ideological tenor of one's tweets (Schulz et al., 2020).
} 
ical diversity and oppositionality of this imagined audience. I will refer to these concepts as subjective (social) network diversity (SND) and subjective (social) network oppositionality (SNO), respectively. In the next section I consider the expected effects of SND and SNO on online political expression.

\section{Hypotheses}

Since we are no longer considering the accumulation of influences in the original sense of the crosspressures thesis, the argument in favor of the negative cross-pressures thesis in the present context depends crucially on whether SNO causes self-censorship owing to fear of social sanction. Recent empirical evidence suggests that people will refrain from online political engagement when they believe that a sufficiently large proportion of their network has divergent political views. Kwon, Moon, and Stefanone (2015), for example, find that discussion network oppositionality is positively associated with willingness to self-censor political expression (WTSC), which in turn has a negative impact on online political posting behavior. Similarly, Liu, Rui, and Cui (2017) show that network oppositionality reduces willingness to express opinions about controversial issues on Facebook.

Arguments for the countervailing positive effect here are relatively weaker. First, since we are not here considering the direct effects of accumulated exposure to countervailing views, it is not clear that arguments based on post-hoc information and the effect of discussion frequency are directly relevant. Second, while certain types of individuals may be predisposed to persuade or correct others, the decision to do so still occurs under the gaze of the imagined audience. According to Correa et al. (2014), extroversion is positively associated with the political use of social media. While we might expect those high in extroversion to be willing to risk social sanction of the imagined audience, it is not clear that this should hold true in general, especially for those who perceive a high degree of oppositionality.

A possible counter argument is that the cost of sanction on social media is quite low, compared to the cost of being publicly sanctioned in an offline context. However, recent research suggests that even a single politely worded direct message can be sufficient to affect a change in online behavior (Munger, 2017). Moreover, because all actions online are globally visible and infinitely replicable the potential consequences of political expression online can be quite severe. JK Rowling, for example, drew the ire of the internet after endorsing ("liking") a transphobic social media post (Assunção, 2020). David Shor was publicly sanctioned by a colleague at the consultancy firm Civis Analytica for sharing science research on Twitter that was deemed insufficiently supportive of the Black Lives Matter social justice movement (Mounk, 2020). These are perhaps extreme cases, but the potential for these types of social sanctions should act as a strong deterrent against political expression that runs counter to the perceived views of one's imagined audience. In sum, people have little to gain and much to lose from engaging in the public expression of political views that may be unpopular or offensive to the imagined audience. Given these potentially disastrous consequences, it would seem unlikely for one to be more likely to engage in politics in an oppositional context than in a supportive one. I thus pose the following hypothesis:

$\mathrm{H} 1: \mathrm{SNO}$ is negatively associated with political expression. 
The expected relationship between SND and political engagement online is perhaps more complicated than that of SNO. On one hand, we might expect the perception of the likelihood of sanction to be positively associated with SND, since the more heterogeneous a given audience is, the more likely there are to be alters predisposed to sanction ego for their political views. On the other hand, we lack much of an empirical or theoretical basis to suppose that this consideration overrides other possible considerations. Indeed, there are many reasons to think that the positive incentives outweigh the negative ones. For instance, it could be the case that SND stimulates political engagement by causing individuals to feel that they are participating in a lively digital environment, analogous to the way proponents of the positive cross-pressures theory argue that heterogeneity stimulates interest in politics. Because existing research does not provide conclusive guidance here, I pose the following research question:

RQ1: What is the effect of SND on political expression online?

Another possibility to consider is that the effect of SND could depend on the global distribution of the thresholds of political participation. Hu, Lin, and Cui (2015) draw on agent-based modelling to show that the effect of local network diversity is extraordinarily sensitive to global initial conditions. Yet, because their results are based on interactions between artificially constructed agents it is not clear that they have direct implications for the effect of subjective network diversity in the sense discussed above. If we assume that individuals have some sense of the distribution of participation thresholds of their imagined audience, and that their subjective assessment of this distribution is a reflection of the actual distribution of participation thresholds, then it might be true that the fundamental dynamics observed by Hu et al (2015) apply here as well. Obviously, this is a strong assumption. Theory and empirical evidence are again inconclusive. I thus pose a second research question:

RQ2: Is the effect of SND on online political expression different where the overall expression level is high than where the overall expression level is low?

\section{Data and Method}

I test the hypothesis posed above by analyzing survey data collected by Qualtrics between August 21, 2018, and September 24, 2018. Quota sampling by age, sex, education, and income was used to ensure that the samples are roughly representative of their respective populations. The resulting data set contains responses from 1,493 respondents $($ Japan $=1,079$, Korea $=414)$.

These countries are chosen for two main reasons. First, the vast majority of studies of the relationship between network heterogeneity and political participation is based on research conducted in the United States or Western Europe. Moreover, there has been almost no consideration of the effect of the national or cultural context on social network dynamics. This study thus contributes to the literature by increasing our knowledge by assessing the generalizability of theories and approaches developed in the West.

Second, by using a cross-case comparison, I can more directly assess the influence of the national context on these dynamics. Specifically, these cases are chosen on the basis of the logic behind the Most Similar Systems Design (MSSD), wherein the goal is to control for as many contextual variables 
as possible, while allowing for difference on the main variables of interest. South Korea and Japan are broadly similar in that they are both stable liberal democracies with collectivist cultures, similar electoral institutions, and similar levels of economic development. By contrast, they have vastly divergent overall levels of online political engagement, with Koreans being far more likely to engage in offline and online political actions and expression than the Japanese (Jenkins, 2019; Barnidge et al., 2018). A full discussion of these differences is beyond the scope of the present study, but they can largely be understood as a consequence of differences in incentives for mass contentious action and differences in political context. Japan is generally ideologically moderate, and the central bureaucracy is embedded in political organizations in such a way as to provide more incentives for behind-the-scenes lobbying than for contentious mass action (Kyung, 2015; Vinken et al., 2010). Korea, by contrast, is more polarized, and national-level collective action is a primary tool of political organizations, which are larger, better staffed, and more deeply connected to individual politicians than their counterparts in Japan (Lee, 2011; Lee \& Arrington, 2008).

Online political expression is important in both contexts, if perhaps in slightly different ways. In the Japanese context, online political expression provides a means for ordinary citizens to engage in politics in a way that is generally not possible given the relatively limited opportunities for political engagement in civil society. In Korea, online political discussion and participation is frequently the catalyst for direct offline political action. Thus, who participates in politics online can have a direct impact on the goals and methods of real-world political action.

The main independent variables are SNO and SND. These are measured by two survey items that ask respondents to rate on a scale of zero to ten how different the people they interact with online are in terms of their political views from 1) the respondent, and 2) each other. ${ }^{3}$ These items yield measures of SNO (from respondent answers to 1) and SND (from respondent answers to 2). The grand mean of SNO is 4.94 (SD: 2.13), and the grand mean of SND is 4.89 (SD: 2.13). These items are designed to tap the perceived heterogeneity of the broader potential audience one might have in mind while engaging in politics publicly on the internet. They differ from most traditional measures of network heterogeneity in two important ways. First, they ask about one's weak-tie group in general rather than specific groups, such as friends, family, or specific subgroups, like discussion network, since the goal is to have respondents conjure a portrait of a generic weak-tie audience, rather than one that is dominated by a few prominent familiar contacts. Second, whereas most studies focus on those with whom individuals discuss politics, these items ask respondents to think more broadly about all those they interact with online, since they are all potential recipients of political messages broadcast by the respondent on social media.

The main dependent variable is a measure of political expression: namely, the frequency of endorsing social media posts that are political in nature. This is measured by a survey item that asks respondents "How often do you 'like' social media posts about politics?" Responses range from none ("zero times per week") to five ("more than ten times per week"). The grand mean of this

\footnotetext{
${ }^{3}$ The precise item wordings are as follows: "Think of the non-family non-friend people with whom you interact or come into contact with online (through social media, SNS, email, internet cafes, comment sections, etc.). Overall, how similar are these people to you in terms of your views on politics? $(0=$ Very Dissimilar, $10=$ Very Similar $)$. Overall, how similar are these people to each other/you in terms of their political views?"
} 
variable is 1.78 (SD: 1.07). As expected, on average Koreans more frequently endorse political posts by about 0.266 on the $1-5$ scale $(95 \%$ CI: $[0.130,0.403])$.

In order to obtain more precise estimates of the associations between the main independent and dependent variables, I add controls for a number of factors that we should expect to be correlated with social media endorsing behavior. Political interest is a well-known predictor of political engagement (e.g., Verba et al., 1995). It is measured by survey items that asks respondents how interested they are in politics ( $1=$ Not at all interested, $5=$ Very interested). The average level of political interest is 3.14 (SD: 1.09).

Frequency of social media use is included because it is a known predictor of online political activity, use of social media for news, and exposure to counter-attitudinal content (Flecther \& KelisNielson, 2017). It is given by an item that asks respondents how many hours per day they use social media. Responses range from "0 Hours" (coded as 1) to "More than 3 Hours" (coded as 5). The grand mean of this variable is 2.74 (SD: 1.10).

Controls for country, age, sex, education, and income are also included. Age is measured by an ordinal variable with seven categories, ranging from 18-24 years (coded as 1) to 71+ years (coded as 7 ). The modal value is 3 (35-44 years). Sex is measured by a categorical variable that takes on the following values: "Male", "Female", and "Other". 46\% of the respondents are female and 53\% are male. Education is given by an ordinal variable that ranges from "No Formal Education" (coded as 1) to "Graduate or Professional School" (coded as 7). The modal value is 4 ("College or University"). Income is indicated by self-placement in income categories that range from "Low Income" to "Upper Income" (coded as 1 and 5, respectively). The modal income value is 3 ("Middle Income").

Finally, ideological extremity is controlled for because these it known to predict online political engagement (Hopp, Ferucci, \& Vargo, 2020). Ideological extremity is measured by an item that asks respondents to rate the strength of their political views. Possible responses range from "Very Weak" (coded 1) to "Very Strong" (coded 7). The average value of this variable is 4.54 (SD: 1.45).

\section{Results}

$\mathrm{H} 1$ is assessed by estimating the relationship between the main independent variables and political post endorsing with OLS (Ordinary Least Squares) regression. The results of the regression are shown in Table 2. ${ }^{4}$ As expected, subjective network oppositionality is negatively associated with the frequency of endorsing political content on social media. The coefficient on SNO is -0.075 , and the $95 \%$ confidence interval for this coefficient ranges from -0.11 to -0.04 . These results indicate that, on average, those with the highest level of SNO will exhibit a 0.37 lower political post endorsement frequency than with those with the lowest level of SNO, holding other factors constant. These results support H1.

\footnotetext{
${ }^{4}$ A number of different model specifications were estimated, including multi-level modelling (MLM) and ordinal logit. The results of the analysis did not significantly differ by model specification.
} 
Table 2. The Relationship between SNO, SND, and Endorsing Behavior (Pooled Models)

\begin{tabular}{lc}
\hline \hline & Dependent Variable: \\
\cline { 2 - 2 } & Endorsement of Political Social Media Posts \\
\hline SND & $0.051^{* * *}(0.019)$ \\
SNO & $-0.075^{* * *}(0.019)$ \\
Use of Internet for News & $0.024(0.025)$ \\
Social Media Use & $0.275^{* * *}(0.030)$ \\
Political Interest & $0.079^{* *}(0.038)$ \\
Ideological Extremity & $0.166^{* * *}(0.029)$ \\
Korea & $-0.023(0.066)$ \\
Age & $0.001(0.024)$ \\
Sex & $0.019(0.062)$ \\
Education & $-0.058^{*}(0.032)$ \\
Income & $0.167^{* * *}(0.032)$ \\
Constant & $-0.189(0.190)$ \\
\hline Observations & 1,021 \\
$\mathrm{R}^{2}$ & 0.273 \\
Adjusted R ${ }^{2}$ & 0.265 \\
Residual Std. Error & $0.936(\mathrm{df}=1009)$ \\
F Statistic & $34.472^{* * *}(\mathrm{df}=11 ; 1009)$ \\
\hline \hline Note: & ${ }^{*} \mathrm{p}<0.1 ;{ }^{* *} \mathrm{p}<0.05 ;{ }^{* * *} \mathrm{p}<0.01$
\end{tabular}

Turning to RQ1, the results of the analysis show that SND is positively associated with the frequency of the endorsing of political content on social media. The coefficient on SND indicates that each additional one-unit increase in subjective network diversity is associated with a 0.051 increase in political engagement online. The $95 \%$ confidence interval for this coefficient ranges from 0.01 to $0.09(\mathrm{p}=0.008)$.

Figure 1 shows a jitter plot of political post endorsement frequency by level of subjective network diversity, along with LOESS smoothing splines in order to provide a better visual expression of the relationship between the variables. Looking from the minimum SND to the maximum SND, we see that Koreans with low SND are much more likely to endorse political posts on social media than Japanese respondents. As SND increases, Korean respondents appear to post less frequently, suggesting that SND reduces engagement. However, this negative effect levels off for those with a SND value of about 6 and higher, and, in fact, there appears to be a slight uptick for those with high values of SND. This overall pattern suggests a quadratic model; that is, a statistical model that includes squared versions of the original variables. By contrast, among Japanese respondents we see that SND has a weak positive relationship with endorsing behavior. Yet, here too, we see some potential non-linearity in the data. 
Figure 1. Jitter Plot of SND and Endorsing Behavior by Country

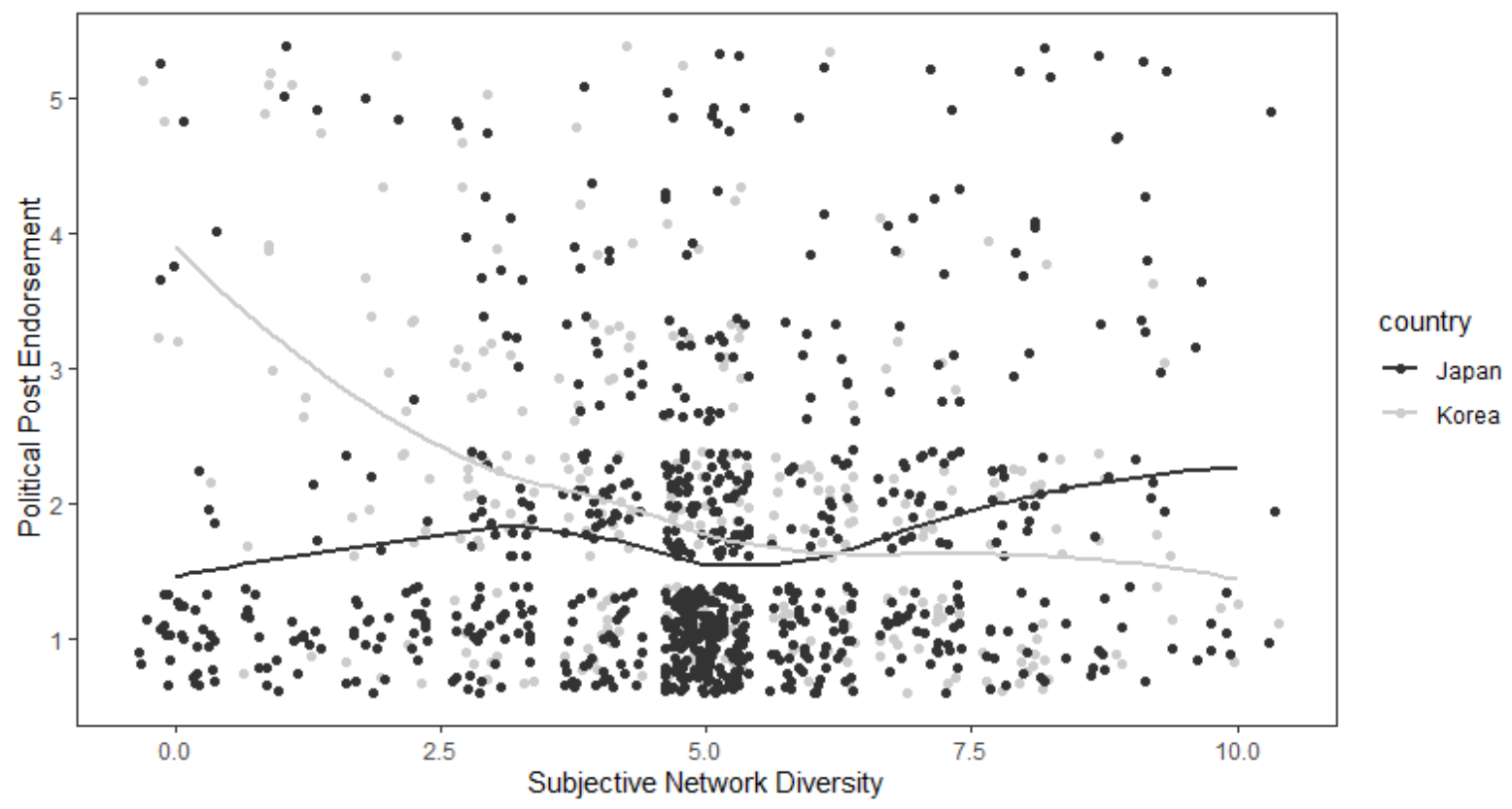

Given these patterns, I approach RQ2 in a couple of ways. First, I add an interactive term to the same model used to test H1. Second, I run two sets of models for each group of respondents: a standard OLS estimate of the untransformed data, and estimates of quadratic models to account for non-linearity in the data. All models are estimated with OLS. The results are presented in Table 3 and Table 4 below.

The results shown in the first column in Table 3 ("Interaction") confirm that the association between SND and endorsing behavior among Korean respondents is about 0.132 lower than that for Japanese respondents $(\mathrm{p}<0.01)$. In fact, looking at the second column, which shows the results for the separate model for Korea, we see that SND is negatively associated with endorsing behavior among Koreans, as is SNO. However, these coefficients are far from statistically significant. 
Table 3. The Relationship between SNO, SND, and Endorsing Behavior

\begin{tabular}{|c|c|c|c|}
\hline & \multicolumn{3}{|c|}{ Dependent variable: } \\
\hline & \multicolumn{3}{|c|}{ Endorsement of Political Social Media Posts } \\
\hline & (Interaction) & (Korea Only) & (Japan Only) \\
\hline SND & $0.084^{* * *}(0.020)$ & $-0.058(0.050)$ & $0.084^{* * *}(0.021)$ \\
\hline Korea & $0.640^{* * *}(0.167)$ & & \\
\hline SNO & $-0.063^{* * *}(0.019)$ & $-0.065(0.051)$ & $-0.061^{* * *}(0.021)$ \\
\hline Use of Internet for New & $0.024(0.025)$ & $0.045(0.051)$ & $0.019(0.029)$ \\
\hline Social Media Use & $0.268^{* * *}(0.030)$ & $0.215^{* * *}(0.053)$ & $0.288^{* * *}(0.037)$ \\
\hline Political Interest & $0.069^{*}(0.038)$ & $0.211^{* * *}(0.066)$ & $-0.004(0.046)$ \\
\hline Ideological Extremity & $0.160^{* * *}(0.029)$ & $0.027(0.059)$ & $0.209^{* * *}(0.034)$ \\
\hline Age & $-0.005(0.023)$ & $0.022(0.039)$ & $-0.019(0.029)$ \\
\hline Sex & $0.027(0.061)$ & $0.113(0.111)$ & $-0.007(0.074)$ \\
\hline Education & $-0.055^{*}(0.031)$ & $-0.149^{* * *}(0.055)$ & $-0.006(0.038)$ \\
\hline Income & $0.156^{* * *}(0.032)$ & $0.149^{* * *}(0.055)$ & $0.167^{* * *}(0.039)$ \\
\hline SND*Korea & $-0.132^{* * *}(0.031)$ & & \\
\hline Constant & $-0.297(0.190)$ & $0.867^{* *}(0.405)$ & $-0.451^{* *}(0.224)$ \\
\hline Observations & 1,021 & 324 & 697 \\
\hline $\mathrm{R}^{2}$ & 0.286 & 0.295 & 0.289 \\
\hline Adjusted $\mathrm{R}^{2}$ & 0.278 & 0.272 & 0.279 \\
\hline Residual Std. Error & $0.928(\mathrm{df}=1008)$ & $0.914(\mathrm{df}=313)$ & $0.929(\mathrm{df}=686)$ \\
\hline F Statistic & $33.700^{* * *}(\mathrm{df}=12 ; 10$ & $3.095^{* * *}(\mathrm{df}=10 ; 3$ & $7.909^{* * *}(\mathrm{df}=10 ; 686)$ \\
\hline
\end{tabular}

Table 4 shows the results of the quadratic models estimated for each group of respondents. In order to compute the models SND was mean-centered. SND^2 indicates the coefficient for the square of this mean-centered version of SND. SNO was excluded from these models because it introduced considerable variance inflation when included (VIF > 4). The results in the first column show that the quadratic model is a better fit for the data than the simple linear models. An analysis of variance was conducted in order to compare the fit of the model in column 1 with the same model without $\mathrm{SND}^{\wedge} 2$. Including the square of SND reduces RSS by about $6.541(\mathrm{p}=0.005)$, suggesting that the quadratic model is indeed a better fit.

The same procedure was conducted for the models estimated on data from the Japanese sample alone. The quadratic model did reduce RSS by about 3.44, but the difference between the two models was only marginally statistically significant $(p=0.047)$. Higher order models (cubic, etc.) were estimated but they did not significantly improve model fit. These results suggest that in a context characterized by high average participation, increases network diversity are associated with decreases but at a decreasing rate. By contrast, in a context characterized by a relatively low average participation, network diversity has weak positive association with endorsing behavior. 
Table 4. The Relationship between SNO, SND, and Endorsing Behavior (Quadratic Models)

\begin{tabular}{lcc}
\hline \hline & \multicolumn{2}{c}{ Dependent variable: } \\
\cline { 2 - 3 } & \multicolumn{1}{c}{ Endorsement of Political Social Media Posts } \\
& $-0.119^{* * *}(0.026)$ & $0.052^{* * *}(0.017)$ \\
\hline SND & $0.025^{* * *}(0.009)$ & $0.010^{* *}(0.005)$ \\
SND $^{2}$ & $0.032(0.050)$ & $0.020(0.029)$ \\
Use of Internet for News & $0.210^{* * *}(0.052)$ & $0.293^{* * *}(0.037)$ \\
Social Media Use & $0.219^{* * *}(0.065)$ & $-0.012(0.046)$ \\
Political Interest & $0.027(0.058)$ & $0.214^{* * *}(0.034)$ \\
Ideological Extremity & $0.021(0.039)$ & $-0.015(0.029)$ \\
Age & $0.105(0.109)$ & $-0.009(0.074)$ \\
Sex & $-0.138^{* *}(0.054)$ & $-0.004(0.038)$ \\
Education & $0.144^{* * *}(0.054)$ & $0.169^{* * *}(0.039)$ \\
Income & $0.177(0.329)$ & $-0.429^{* *}(0.207)$ \\
Constant & 324 & 697 \\
\hline Observations & 0.309 & 0.285 \\
$\mathrm{R}^{2}$ & 0.287 & 0.274 \\
Adjusted $\mathrm{R}^{2}$ & $0.905(\mathrm{df}=313)$ & $0.932(\mathrm{df}=686)$ \\
Residual Std. Error & $13.999^{* * *}(\mathrm{df}=10 ; 313)$ & $27.283^{* * *}(\mathrm{df}=10 ; 686)$ \\
F Statistic & & ${ }^{*} \mathrm{p}<0.1 ;{ }^{* *} \mathrm{p}<0.05 ;{ }^{* * *} \mathrm{p}<0.01$ \\
\hline \hline Note: & &
\end{tabular}

\section{Conclusion}

The debate over the effect of political cross-pressures is important, having both theoretical and direct practical consequences for democracy. I have argued that this debate is often couched in the parlance of an earlier era, and that it could benefit from an update. I have taken one step towards this task by resituating the cross-pressures debate in a way that takes into account the unique environment individuals face in deciding whether to engage in political expression on social media, and I have proposed two factors that may be important in individuals' decisions about whether to engage in political expression online: subjective social network diversity and subjective social network oppositionality. I have suggested that these are related to compositional and discussion heterogeneity, but that they constitute distinct concepts in their own right. I view these as factors that operate in addition to the cross-pressures that take place in the real world.

The descriptive analysis conducted here suggests that SNO has a fairly unambiguous negative association with political expression, whereas the relationship between SND and political expression is somewhat more complex. In Japan, a country characterized by low levels of non-institutional political participation, SND exhibits a fairly linear positive association with political expression, whereas in Korea it exhibits a non-linear negative relationship with political expression. 
This study leaves a number of empirical and theoretical challenges for future studies. First, while subjective network heterogeneity is related to compositional and discussion network heterogeneity, the present data do not permit further empirical investigation of this relationship. Future studies should aim to identify the empirical and theoretical connections between these two concepts. Second, future studies can improve on the measures of subjective network heterogeneity presented here. One's imagined audience will likely vary by social media platform. Hence, the characteristics of the audience might also vary according to which platform one has in mind. As Schulz et al. (2020) have suggested, for those who predominantly use Twitter - or are prompted to think of Twitter specifically - this audience might be Twitter followers. By contrast, for those who primarily use Facebook it might be a combination of acquaintances, family, and friends. Future studies can explore how SND and SNO vary according to platform.

The findings with regard to SNO have important implications for digital democracy. If it is true that SNO causes people to refrain from political expression online, then it is likely that those who are not as affected by SNO are going to play a stronger role in online discussion. While the present study has made some attempt to control for the influence of ideological extremity, it is possible that those who are undeterred by SNO may be extroverted, politically extreme, or some combination of these. I leave it to future studies to explore the extent to which this relationship is causal, as well as the potential effects on online political discussion.

The present study is not without limitations. Above all, it is cross-sectional observational data, hence is subject to the usual caveats (lack of ability to infer causality, potential for omitted variable bias, etc.). Also, it draws on cases from one particular geographical region, hence might have limited generalizability. Future scholars can overcome these limitations by examining how context moderates the effect of SNO and SND through careful comparative studies. Finally, there is the inherent difficulty of studying silence. The results of the analysis with regard to SNO suggest that individuals who perceive their digital audience as having political views opposed to their own will refrain from political expression online. To what extent is this true? How can we better empirically measure digital political silence with observational data? For those who do engage in expression, do they do so in a way that reflects their actual views, or do they mimic what they feel to be the views of their audience? I urge researchers to engage with these questions in innovative ways that delve into our increasingly digitally networked lives.

\section{References}

Almond, G., \& Verba, S. (1963). The civic culture: Political attitudes and democracy in five nations. NJ: Princeton University Press.

Asch, S.E. (1951). Effects of group pressure on the modification and distortion of judgments. In H. Guetzkow (Ed.), Groups, leadership and men (177-9). Pittsburg, PA: Carnegie.

Assunção, M. (2020, May). J.K. Rowling likes another anti-transgender tweet. New York Daily News. 
Bakshy, E., Messing, S., \& Adamic, L.A. (2015). Exposure to ideologically diverse news and opinion on Facebook. Science, 348(6239), 1130-32. doi:10.1126/ science. Aaa1160.

Barberá, P. (2014). "How social media reduces mass political polarization: Evidence from Germany, Spain, and the United States." Working Paper. http:// pablobarbera.com/static/ barbera-polarization-social-media.pdf.

Barnidge M, Huber B, de Zúñiga HG, \& Liu J.H. (2018). Social media as a sphere for "risky" political expression: A twenty-country multilevel comparative analysis. The International Journal of Press/Politics, 23(2), 161-182. doi:10.1177/1940161218773838

Bode, L. (2012). Facebooking it to the polls: A study in online social networking and political behavior. Journal of Information Technology \& Politics, 9(4), 352-69. doi:10.1080/19331681.2012.709045.

Chadwick, A. (2017). The hybrid media system: Politics and power. UK: Oxford University Press.

Correa, T., \& Jeong, S.H. (2011). Race and online content creation: Why minorities are actively participating in the web. Information, Communication \& Society, 14(5), 638-59. doi:10.1080/1369118X.2010.514355.

Dodds, P.S., \& Watts, D.J. (2005). A generalized model of social and biological contagion. Journal of Theoretical Biology, 232, 587-604.

Eady, G., Nagler, J., Guess, A.M., Zilinsky, J., \& Tucker, J. (2019). How many people live in political bubbles on social media? Evidence from linked survey and Twitter data. SAGE Open.

Eveland, W.P. Jr., \& Hively, M.H. (2009). Political discussion frequency, network size, and 'heterogeneity' of discussion as predictors of political knowledge and participation. Journal of Communication, 59(2), 205-24. doi:10.1111/ j.14602466.2009.01412.x.

Fletcher R, Cornia A, \& Nielsen RK. (2020). How polarized are online and offline news audiences? A comparative analysis of twelve countries. The International Journal of Press/Politics 25(2), 169195. doi:10.1177/1940161219892768

Garrett, R.K., \& Stroud, N.J. (2014). Partisan paths to exposure diversity: Differences in pro-and counter-attitudinal news consumption. Journal of Communication 64(4), 680-701. doi:10.1111/jcom.12105.

Green, M.C., Visser, Penny S., \& Tetloc, P.E. (2000). Coping with accountability cross-pressures: Low-effort evasive tactics and high-effort quests for complex compromises. PSPB, 26(11), 1380-1391.

Guess, A.M. (2020). (Almost) everything in moderation: New evidence on Americans' online media diets. American Journal of Political Science.

Guess, A.M., \& Coppock, A. (2018). Does counter-attitudinal information cause backlash? Results from three large survey experiments. British Journal of Political Science. 
Habermas, J. (1996). Between facts and norms: Contributions to a discourse theory of law and democracy. Translated by William Rehg. Cambridge, MA: MIT Press.

Halupka, M. (2018). The legitimisation of clicktivism. Australian Journal of Political Science, 53(1), 130-141.

Highfield, T., \& Leaver, T. (2016). Instagrammatics and digital methods: studying visual social media, from selfies and GIFs to memes and emoji. Communication Research and Practice, 2(1), 4762.

Hochschild, J.L. (1981). What's fair? American beliefs about distributive justice. Cambridge, MA: Harvard University Press.

Hopp, T., Ferucci, P., \& Vargo, C. (2020). Why do people share ideologically extreme, false, and misleading content on social media? A self-report and trace data-based analysis of counter media content dissemination on Facebook and twitter. Human Communication Research, 00, 1-38.

Hu, H.H., Lin, J., \& Cui, W.T. (2015). Local opinion heterogeneity and individual participation in collective behavior: a reconsideration. Journal of Artificial Societies and Social Simulation, 18(2).

Huckfeldt, R., Mendez, J., \& Osborn, T. (2004). Disagreement, ambivalence, and engagement: The Political consequences of heterogeneous networks. Political Psychology, 25(1), 65-95.

Jenkins, M. (2019). Explaining cross-country variation in collective action in the digital era. Journal of Information Technology \& Politics, 16(1).

Kim, Y.H. (2011). The contribution of social network sites to exposure to political difference: The relationships among SNSS, online political messaging, and exposure to cross-cutting perspectives. Computers in Human Behavior, 27(2), 971-77. doi:10.1016/j. Chb.2010.12.001.

Kwak N., Williams, A.E., Wang, X., \& Lee, H. (2005). Talking politics and engaging politics: An examination of the interactive relationships between structural features of political talk and discussion engagement. Communication Research, 32(1), 87-111. doi:10.1177/0093650204271400

Kwon, K.H., Moon, S.I., \& Stefanone, M.A. (2015). Unspeaking on Facebook? testing network effects on self-censorship of political expressions in social network sites. Quality \& Quantity, 49(4), 1417-35.

Kyung, J.H. (2015). Japanese Voters' Ideology and Party Choice in the 2012 House of Representatives Election. $\square \square$ 研 $\square \square \square, 45,92-122$.

Lazarsfeld, P.F., Berelson, B., \& Gaudet. (1948). The people's choice: How the voter makes up his mind in a presidential campaign. New York: Columbia University Press.

Lee, J.K., Choi, J.H., Kim, C.S., \& Kim, Y.H. (2014). Social media, network heterogeneity, and opinion polarization. Journal of Communication, 64(4), 702-722. doi:10.1111/jcom.12077. 
Lee, S. J. \& Arrington, C. (2008). The politics of NGOs and democratic governance in Korea and Japan. Pacific Focus, 23(1), 75-96.

Liu, Y., Rui, J.R., Cui, X. (2017). Are people willing to share their political opinions on Facebook? Exploring roles of self-presentational concern in spiral of silence. Computers in Human Behavior, 76: 294-302.

Livingstone, S. (2008). Taking risky opportunities in youthful content creation: Teenagers' use of social networking sites for intimacy, privacy and self-expression. New Media \& Society, 10 (3), 393411. doi:10.1177/1461444808089415.

Margetts, H., John, P., Hale, S., \& Yasseri, T. (2015). Political turbulence: How social media shape collective action. NJ: Princeton University Press.

Marwick, A.E. \& boyd, D. (2011). I tweet honestly, I tweet passionately: Twitter users, context collapse, and the imagined audience. New Media \& Society, 13(1), 114-133. Doi.org/10.1177/146144481036531

Mounk, Y. (2020, June). Stop firing the innocent. The Atlantic.

Munger, K. (2017). Experimentally reducing partisan incivility on twitter. pp. 1-31. URL: http://cess.nyu.edu/wp-content/uploads/2017/02/Dont-@-Me.pdf

Mutz, D. (2002). The consequences of cross-cutting networks for political participation. American Journal of Political Science, 46 (4), 838-55.

Mutz, D. (2006). Hearing the other side: deliberative versus participatory democracy. New York: Cambridge University Press

Nechushtai, E., \& Lewis, S.C. (2019). What kind of news gatekeepers do we want machines to be? Filter bubbles, fragmentation, and the normative dimensions of algorithmic recommendations. Computers in Human Behavior, 90, 298-307.

Nir, L. (2005). Ambivalent social networks and their consequences for participation. International Journal of Public Opinion Research, 17 (4), 422-42.

Nir, L. (2011). Disagreement and opposition in social networks: Does disagreement Discourage turnout? Political Studies 59(3): 674- 692.

Noelle-Neumann, E. (1993). The spiral of silence: public opinion, our social skin. Chicago: The University of Chicago Press.

Prior, M. (2006). Post-broadcast democracy. Cambridge, England: Cambridge University Press.

Scheufele, D.A., Nisbet, M.C., Brossard, D. \& Nisbet, E.C. (2004). Social structure and citizenship: examining the impacts of social setting, network heterogeneity, and informational variables on participation. Political Communication, 21(3), 315-38. 
Schulz, et al. (2020). (Mis)representing ideology on Twitter: How social influence shapes online political expression. Unpublished manuscript.

Steinert-Threlkeld, Z. (2017). Spontaneous collective action: Peripheral mobilization during the Arab spring. American Political Science Review, 111(2), 379-403.

Sun, Y., Shen, L.J., \& Pan, Z.D. (2008). On the behavioral component of the third-person effect. Communication Research 35 (2), 257-78. doi:10.1177/0093650207313167.

Thorson, E. (2014). Beyond opinion leaders: How attempts to persuade foster political awareness and campaign learning. Communication Research 41(3), 353-74. doi: 10.1177/0093650212443824.]

Verba, S., Schlozman, K.L., \& Brady, H.E. (1995). Voice and equality: civic voluntarism in American politics. Cambridge, MA: Harvard University Press.

Vinken, H., Nishimura, Y., White, B.L.J., Deguchi, M. (Eds.). Civic engagement in contemporary Japan established and emerging repertoires. New York: Springer.

Zaller, J. (1992). The nature and origins of mass opinion. Cambridge, UK: Cambridge University Press.

\section{About the Author}

Matthew David Jenkins

Matthew David Jenkins is an Assistant Professor in the Department of Political Science and Diplomacy at Gyeongsang National University in Jinju, Republic of Korea. His research focuses on the relationship between technology, political culture, and political behavior. 